\title{
THE CONDUCTIVITY OF THE ATMOSPHERE AT HIGH
} VOLTAGES.

\author{
BY HARRIS J. RYAN.
}

\section{SyNOPSIS.}

The present paper gives an analysis of the factors that are responsible for the nature of the atmospheric loss occurring on high-voltage lines as reported by Mr. Charles F. Scott in his paper that was published in the A.I.E.E. Transactions, Vol. XV., p. 531, 1898, based upon results obtained by himself and those obtained by Mr. Ralph D. Mershon. The analysis shows that the equation

$E_{\max }=2055 \log _{10}\left(\frac{s}{r}\right) D^{\prime}(r+d) \times 10^{10}$

expresses the relation between the voltage, conductor sizes, anu separation at which the sudden rise occurs in the curve of "loss between wires" at ordinary barometric pressures and temperatures wherein

$E_{\max }=$ the maximum value of the voltage-wave applied to the line.

$r \quad=$ the radius of the line conductor in inches.

$s=$ the separation of the line conductors from center to center in inches.

$d \quad=$ the distance from the conductor surface at which the strain due to the electrostatic field causes initial atmospheric rupture.

$D^{\prime}=$ the strength of the electrostatic field of force (dielectric fux-density) that will electrically rupture the atmosphere at the distance $d$ from the surface of the conductor having a radius $r$ measured in coulombs per square inch. 
To this is added an account of the experiments that were made to determine the above values of $d$ and $D^{\prime}$ in relation to $r$ and the effects due to barometric pressure and temperature changes and to the presence of moisture.

The values found for $d$ and $D^{\prime}$ in relation to $r$ at a barometric pressure of 29.5 inches of mercury and a temperature of $70^{\circ}$ fahr. are given in the following table:

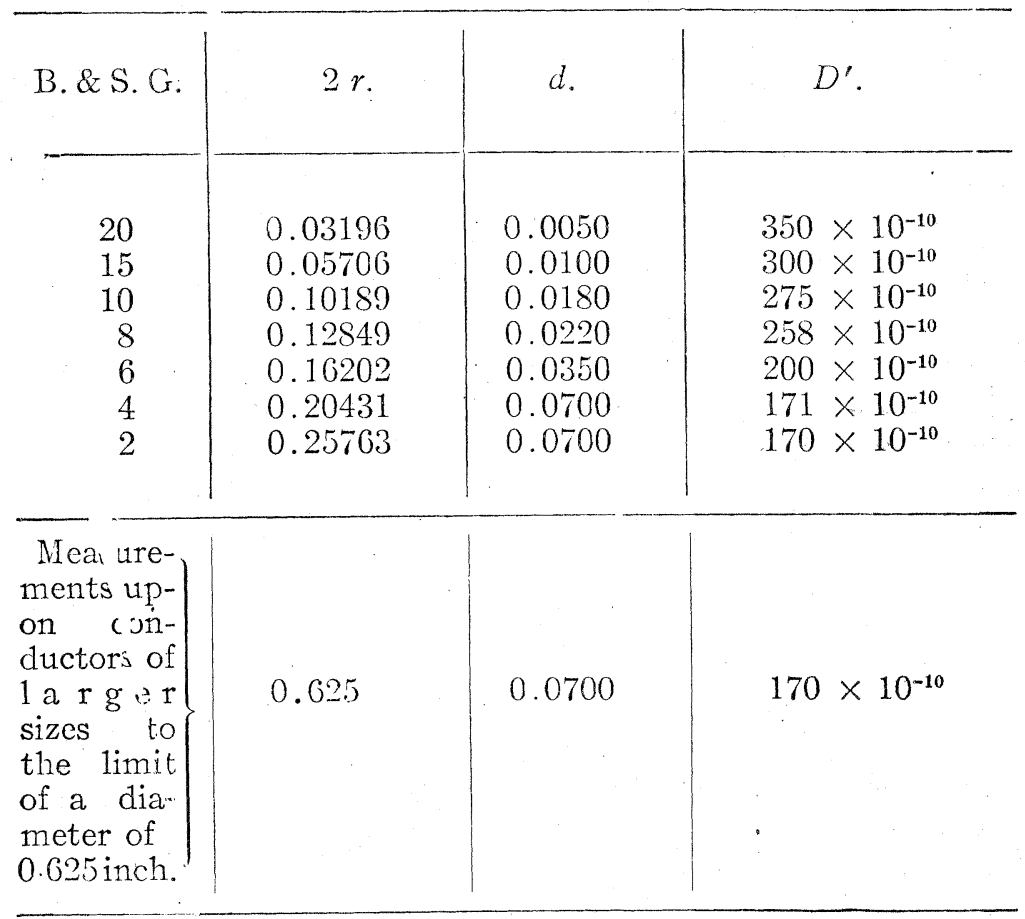

The cxperiments demonstrated that the voltage at which the atmospheric line loss is inaururated varies as the atmospheric density; i.e., directly as the barometric pressure and inversely as the absolute temperature. On substitution of corresponding values obtained by experiment, equation (10) takes the following practical form:

$E_{\max }=\frac{17.94 b}{459 .+t} \times 2055 \log _{10}\left(\frac{s}{r}\right) D^{\prime}(r+d) \times 10^{10}$

wherein

$b=$ the barometric pressure in inches of mercury.

$t=$ the temperature in degrees Fahrenheit. 
Since the values of $d$ and $D^{\prime}$ are constant for diameters of conductors larger than $0.250 \mathrm{inch}$, it follows that equation (12) for corresponding conductors reduces to

$E_{\max }=\frac{17.94 b}{459+t} \times 350000 \log _{10}\left(\frac{s}{r}\right)(r+.07)$

The results obtained by calculation employing equations (12) and (13) are compared with the measurements made by Mershon on the Telluride high-altitude line in 1898 and those obtained by Professor Harold B. Smith upon the Worcester Polytechnic Institute laboratory line in 1901 and 1902 at ordinary altitudes.

Efforts were made to determine the effects of the presence of moisture upon the point at which the atmosphere about highvoltage lines becomes conductive, i.e., upon the point at which the sudden rise in the loss-curve occurs. However, no definite effect of this sort could be found, and this is practically in accord with Mershon's conclusions after his observations made upon the Telluride line under variable weather conditions. If there is such an effect it must be small.

The following table of values has been calculated by means of equations (12) and (13). It shows the corresponding diameters of line conductors that must be employed to avoid loss between wires for a series of line voltages wherein the barometric pressure is 29.5 inches of mercury, the temperature $70^{\circ}$ fahr., and the distance between the conductors 48 inches.

\begin{tabular}{c|c|c|c}
\hline $\begin{array}{c}\text { Maximum volts } \\
\text { at which } \\
\text { atmospheric } \\
\text { conduction loss } \\
\text { occurs. }\end{array}$ & $\begin{array}{c}\text { Corresponding } \\
\text { effective volts } \\
\text { (sine wave) }\end{array}$ & $\begin{array}{c}\text { Operating } \\
\text { pressure, 90 per } \\
\text { cent of corres- } \\
\text { ponding effective } \\
\text { volts. }\end{array}$ & $\begin{array}{c}\text { Diameters of } \\
\text { conductors in } \\
\text { inches. }\end{array}$ \\
\hline & & & \\
78500 & 55000 & 50000 & 0.058 \\
118000 & 83300 & 75000 & 0.106 \\
157000 & 111100 & 100000 & 0.192 \\
235500 & 166600 & 150000 & 0.430 \\
314000 & 222200 & 200000 & 0.710 \\
392000 & 277700 & 250000 & 0.990 \\
\hline
\end{tabular}

The real voltage limit to-day in transmission is due to the insulator, where the line has to be exposed to the weather. In the future the insulator difficulty will be solved in one way or another and higher voltages will be used. Possibly in large undertakings the line may be protected from the elements by means of a con- 
tinuous covering. It is evident that when such high voltages are employed atmospheric conduction, or "the brush" (as one experienced high-voltage engineer termed it in conversation with the writer), must be avoided. High voltage brush discharge was studied and reported upon in the A.I.E.E. Transactions by Dr. Steinmetz.* He applied to it the term corona. The present paper shows that the brush discharge or corona occurs always when a definite strain exists in the atmosphere next to the high-voltage conductors, and that to avoid such corona with its destructiveness and waste of power it is necessary on transmission lines and auxiliaries to proportion things so as to keep the dielectric strain of the atmosphere below a definite point above which the corona will inevitably develop.

In the above table a factor of safety of 1.11 or a margin of 10 per cent has been allowed in estimating the safe voltage at which to operate so as to avoid losses due to brush discharge. This is a laboratory conclusion only. In application the following points must be kept in mind:

1. Without special care there will be doubt in advance as to the exact value that the voltage wave will not exceed. Almost invariably the line-charging current will cause important linevoltage wave-distortion so that the maximum of the wave will exceed the effective value of the voltage by a factor much greater than the square root of two. The corona formation depends primarily upon the maximum and not upon the effective value of the wave; this has been found by Scott, Mershon and others, as well as in the present experiments.

2. One must remember that unless the insulators are properly proportioned, after the cross-arms and pins have been exposed to the weather for some time and have become conductive, the presence of the insulators made of material that has a considerably greater permeability to dielectric flux (greater specific inductive capacity) than the atmosphere, will cause corona to a greater or less degree to form over the conductors in their neighborhood, even if the line has been proportioned so as to avoid corona or atmospheric conduction over the remaining portion of the conductors. The presence of corona upon the conductors in the neighborhood of the insulators will likely be accompanied by corona over the pins inside the insulators, resulting in their

*Transactions A.I.E.E., Vol. X, p. 85, 1893. 
ultimate injury if made of wood from this cause alone, even if the surface leakage current is so limited as not to injure the pin.*

In view of the above it is evident that practical experience and not the laboratory must eventually determine the factor of safety that should be allowed under given circumstances in lieu of the 1.11 factor or the 10 per cent margin allowed in the above table.

The paper closes with the suggestion that when viewed in the dark the corona formed upon wires of given diameters and distances apart provides a method for gauging high voltages that is free from the short-circuit and surging disturbances occasioned by the use of the spark-discharge method. Either two parallel conductors or a conductor mounted at the center of a cylinder may be employed for this purpose.

Former Studies of Atmospheric Conduction.

The atmosphere is ordinarily the general medium in which electric circuits and apparatus are immersed. It is depended upon to a greater extent for insulation than any other medium or material.

Its dielectric strength to resist disruption by electric forces, in bulk, under ordinary conditions as to temperature, barometric pressure and entrained moisture, from an engineering point of view, has been the subject of extensive and critical investigation by Steinmetz, whose results have been communicated to the Institute in several papers.

Steinmetz found in his studies of the electric disruptive strength of the powerful solid dielectrics that the atmosphere surrounding the solid dielectric specimen and the electrodes applied thereto would break under the strain formed by the flux of electric force through it, much more readily than the solid dielectric. This gives rise to envelopes of conductive atmosphere located around the electrodes and over the surfaces of the powerful dielectrics. This phenomenon, which has the appearance of the familiar brush discharges so easily obtainable in electrostatic experiments was studied at some length and he applied to it the term corona.

Scott subsequently investigated experimentally the conditions under which the atmosphere in close proximity to high-voltage lines is subjected to electric stresses that bring it to the breaking point, causing the formation of brush discharges accompanied by losses of power in measurable amounts. Mershon,

*Burning of Wooden Pins on High-Tension Transmission Lines by C. C. Chesney, Transactions A.I.E.E., Vol. XX., p 435, March 22, 1903. 
independently of Scott, carried out a series of experiments at Telluride, Colorado, in which losses between wires due to high voltage were measured on a line 2.25 miles long, whereon the conductors having a diameter of 0.162 inch were mounted at various distances apart and between which pressures varying from 20000 to 60000 volts were applied. The results obtained through this series of investigations by Mershon and by Scott and his co-workers were reported by Scott to the Institute in a paper at the June meeting in 1898 .

The characteristic phenomena of greatest interest to the engineer, as brought out in this classic paper, are those to which the Telluride curves of voltage and line-loss apply and which are charted in Fig. 6, Vol. XV., p. 545, as determined by Mershon and which for convenience is reproduced as Fig. 1 of the present paper.

The experimental and analytical study upon which this paper is based was undertaken for the purpose of securing further knowledge of the nature of the line-loss as observed by the above gentlemen.

The Electrostatic Field.

When the terminal faces of a dielectric are in contact with conductors between which an electromotive force is applied, an electric force is exerted throughout the dielectric in variable degree, according to the position with reference to conductors. This electric force produces a distortion of the atomic structure of the dielectric; i.e., a displacement of the electrons forming the dielectric atoms. Such, electron-displacement, while in progress, constitutes an electric current. The displacement encounters the reaction due to internal atomic forces which tend to maintain the original structural form. This reaction is the cause of the formation of the familiar counter electromotive force of a condenser and is in proportion to the total amount of electricity or the time-integral of the current that was passed through the dielectric. When the process of atomic distortion proceeds beyond the point of structural rupture, the ordinary conductioncurrent ensues. Thus through a dielectric prior to the rupturing point the only current that can be passed is a displacement current. The passage of such displacement current and the establishment of the corresponding field of electrostatic force are merely cause and effect in one and the same operation. In any portion of the dielectric the value of the strength of the electrostatic field of force therein established is proportional to the 
displacement of electricity, i.e., to the time-integral of the displacement current that accompanied the establishment of such electrostatic field, For engineering purposes, therefore, the time-integral of displacement current may be conveniently employed as a measure of the strength of the corresponding electrostatic field of force.

The energy that is taken up in the formation of an electrostatic field of force per unit dielectric volume and which has been applied, therefore, in the passage of the corresponding timeintegral of displacement current, is

$$
J=\frac{1}{2} C E^{2}
$$

where $C$ is the capacity in farads; i.e., the coulombs of displacement current per volt.

When an electromotive force of one volt is applied to the opposite faces of a centimetre-cube of air at ordinary barometric pressure and temperature, the energy taken up by the electrostatic field formed thereby throughout the cube, will be

$$
441.7 \times 10^{-10} \text { joules }
$$

No important change in this value occurs with variation of barometric pressure and temperature. When it is substituted in equation (1) the corresponding strength of electrostatic field thus produced per volt per centimetre of air expressed in coulombs of displacement current per square centimetre is found to be

$$
C=883.4 \times 10^{-10}
$$

For present convenience strength of electrostatic field of force will be referred to as density of dielectric flux. It may, therefore, be stated with reference to the dielectric permeability of air that,

One volt applied through a distance of one centimetre in air will establish a dielectric flux density of $883.4 \times 10^{-10}$ coulombs per square centimetre.

This is the same thing as the capacity in farads of a condenser having surfaced electrodes of one square centimetre each, facing opposite sides of a centimetre cube of air.

In this method of designation it follows that the density of dielectric flux established per volt per unit area of conductorterminal face is equal to the capacity in farads per unit area of such face. Thus in connection with a transmission line the total dielectric flux set up between conductors per unit length will be the product of the capacity of such unit length of line in farads and the applied electromotive force. The corresponding 
density of dielectric flux extending from the surface of either conductor is the total flux per unit length divided by the corresponding conductor surface.

\section{Analytical Study of Mershon's Results.}

From the work of Steinmetz it is known that

$a$. The atmosphere and the gases generally, conduct after disruption in two forms:

1. Arcs or very hot streamers. A concentrated conduction at high current-density.

2. Corona or brush discharge. A diffused conduction at low current-density, developing heat at lower intensity.

b. 1. The dielectric strength of the atmosphere in bulk is such as to require for rupture approximately a pressure-gradient of 10000 sine wave effective volts per inch.

2. The thin zones of atmosphere that enclose the electrode and which are in immediate contact therewith have a far greater dielectric strength than air in bulk, corresponding to a ratio of dielectric strengths of from five to ten.

From the nature of sparking discharges through air the conclusion is reasonable that whenever the flux of electric force, or more briefly the dielectric flux, through the air in a given state as to temperature, pressure, and freedom from foreign material, rises to a certain value an atomic structural rupture of the air will occur, resulting in conduction.

From Steinmetz's results it is evident that this maximum value of dielectric flux-density at which atmospheric disruption will not occur will depend upon the position of the particular portion of the atmosphere being considered relative to the conductors or electrodes between which the high voltage is applied.

The classic electrostatic experiments as well as the modern Paschen's law,* which has been tested to above five atmospheres and which asserts that the sparking discharge voltage through given distances in air increases with the atmospheric density and, therefore, as the pressure and inversely as the temperature on the absolute scale, make it reasonable to conclude that the minimum dielectric flux density that will cause atmospheric conduction will vary as the atmospheric density and therefore directly as the barometric pressure and inversely as the temperature on the absolute scale.

\footnotetext{
*Conductivity of Electricity through Gases. J. J Thomson, Edition cf 1903, p. 367.
} 
The researches of Hittorf, Crooks, J. J. Thomson and others, including some recent work upon this particular point by Dr. Blaker, make it reasonable to conclude that so far as concerns magnitudes which are appreciable in engineering, the atmosphere under ordinary conditions and fairly clean, i.e., free from floating

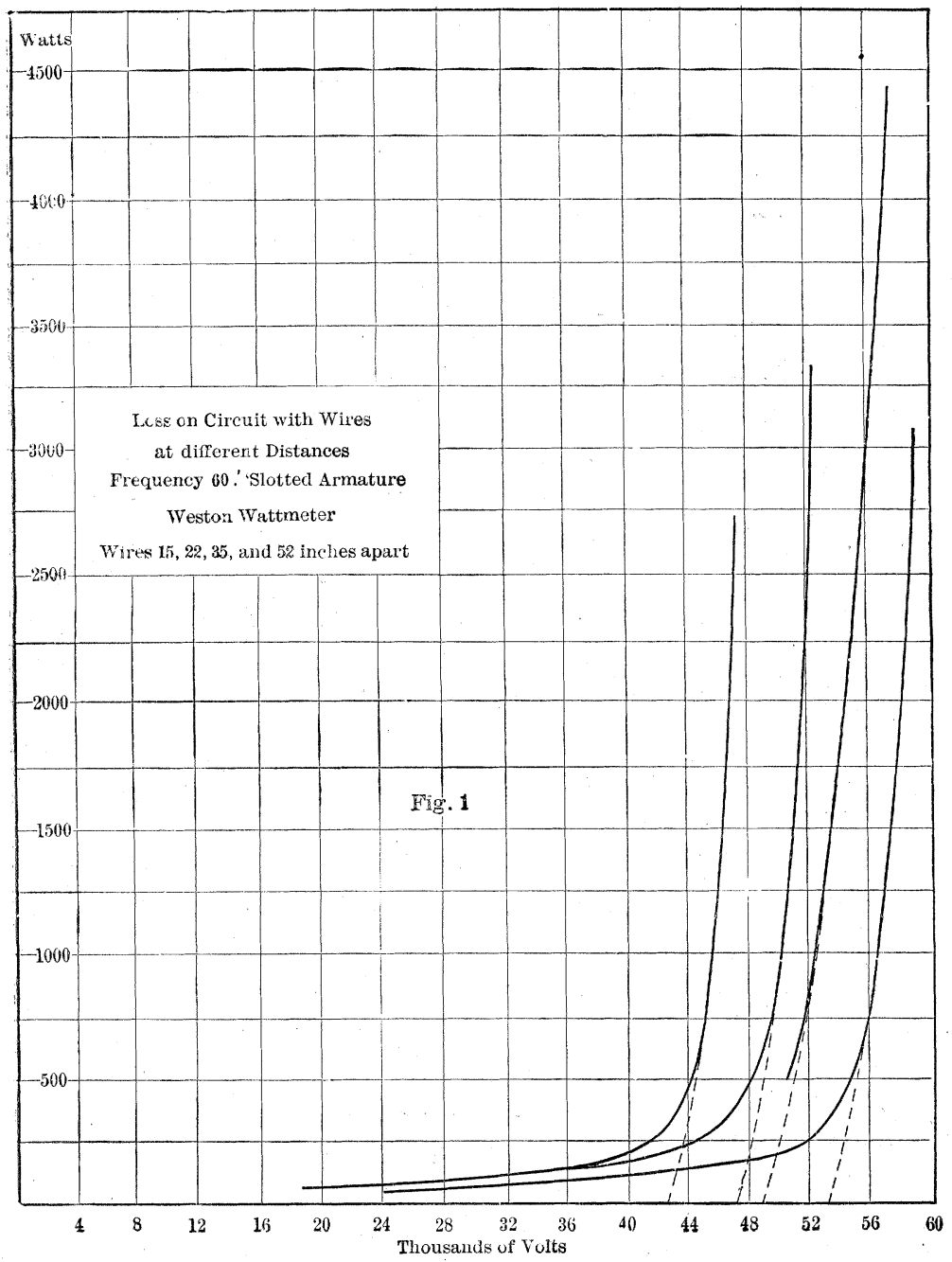

FIG. 1.

conducting material, will not conduct appreciably in the neighborhood of high voltage lines when their surfaces are bare, so long as no portion of such atmosphere is permeated with a dielectric flux that is not sufficient to cause rupture at any one point. 
When the dielectric flux exceeds the rupturing point, conductivity ensues and there is a conductive transfer of current from conductor to conductor through the atmosphere.

On continuous-current circuits the amount of transfer of such current must be small prior to the application of a voltage sufficient to break entirely through the dielectric atmosphere from conductor to conductor, when the familiar arcing discharge occurs, amounting in an engineering equipment to a short-circuit.

On alternating-current circuits, as long as none of the atmosphere in the neighborhood of high-voltage conductors is ruptured, transfer will occur only of capacity charging current which is in leading quadrature with the voltage. However, as soon as the zones of atmosphere immediately surrounding the conductors are subjected to a dielectric flux exceeding the rupturing point, such zones become conductive, thereby doing two things:

1. The effective diameter of the conductor is increased by the presence of the conducting zone, thereby increasing the capacity of the line and consequently the charging current.

2. The presence of the conducting zone must act in effect to produce a high resistance which the charging current must traverse. This must produce a lag in the charging current causing it to have a power-component in phase with the voltage. In effect such action is the same as though the power-component of the current were conductively transferred through the atmosphere.

Where the conductors of a high-voltage transmission line are separated a distance between centers of more than 20 diameters, the dielectric flux passes from the surface of a conductor of round section at a density that is so nearly uniform about the circumference that it may for practical purposes, in the present instance, be assumed constant. In discussing these relations further the following symbols will be used:

$C$, the capacity of the line in farads per inch of length.

$s$, the distance between the conductors in inches.

$r$, the radius of the conductors in inches.

$\phi_{0}$, the total dielectric flux established from conductor to conductor, measured in terms of the corresponding displacement current; i.e., in coulombs.

$D_{0}$, the dielectric flux-density at the surface of the conductor in coulombs per square inch of sectional area.

$D^{\prime}$, the corresponding dielectric flux-density at a distance slightly remote from the surface of the conductor, where the 
extraordinary dielectric strength of the atmospheric zone ceases and where occurs the region of greatest dielectric strain relative to the disruptive strength.

$D$, the corresponding dielectric flux density at any point.

The capacity between wires in farads per inch of line is

$$
C=\frac{0.00306}{\log _{10}\left(\frac{s}{r}\right)} \times 10^{-10 *}
$$

The total displacement current and, therefore, the total dielectric flux established between conductors per inch of line at the line voltage, $E$, is

$$
\phi_{0}=E C=\frac{0.00306}{\log _{10}\left(\frac{s}{r}\right)} \times E \times 10^{-10}
$$

The dielectric flux density at the surface of the conductor is

$$
\begin{aligned}
& D_{0}=\frac{\phi_{0}}{2 \pi r} \\
& D_{0}=\frac{0.00306}{2 \pi r \log _{10}\left(\frac{s}{r}\right)} \times E \times 10^{-10}
\end{aligned}
$$

At a radial distance $d$ from the surface of the conductor, the corresponding dielectric flux density is

$$
\begin{gathered}
D^{\prime}=\frac{\phi_{0}}{2 \pi(r+d)} \\
D^{\prime}=\frac{0.00306}{2 \pi(r+d) \log _{10}\left(\frac{s}{r}\right)} \times E \times 10^{-10}
\end{gathered}
$$

In alternating-current work the maximum values of $D_{0}$ and $D^{\prime}$ are wanted, and the maximum values of the voltage waves must, therefore, be used for $E$, as reduced from equations (7) and (8), thus:

$$
\begin{aligned}
& E_{\max }=2055 \log _{10} \cdot\left(\frac{s}{r}\right) \cdot r \cdot D_{0} \times 10^{-10} \\
& E_{\max }=2055 \log _{10} \cdot\left(\frac{s}{r}\right)(+d) D^{\prime} \times 10^{-10}
\end{aligned}
$$

When Mershon's results given in Fig. 1 were used to test these equations it was found that they correctly accounted for the relation between the separation of the conductors and the voltage at which the initial brush discharge took place. These results gave also a certain value for $D_{n}$ which would not give correct *Perrine and Baum, Trans., A. I. E. E., Vol. XVII., p. 3ô2, May 18, 1900. 
results when used to determine the voltage required to start the line loss for the small wires used by Scott in some of his experiments at Pittsburg.

At this point a rough laboratory test was made to see whether one would find the start of the loss between wires to occur at the same voltages for the same size of conductor and distances apart

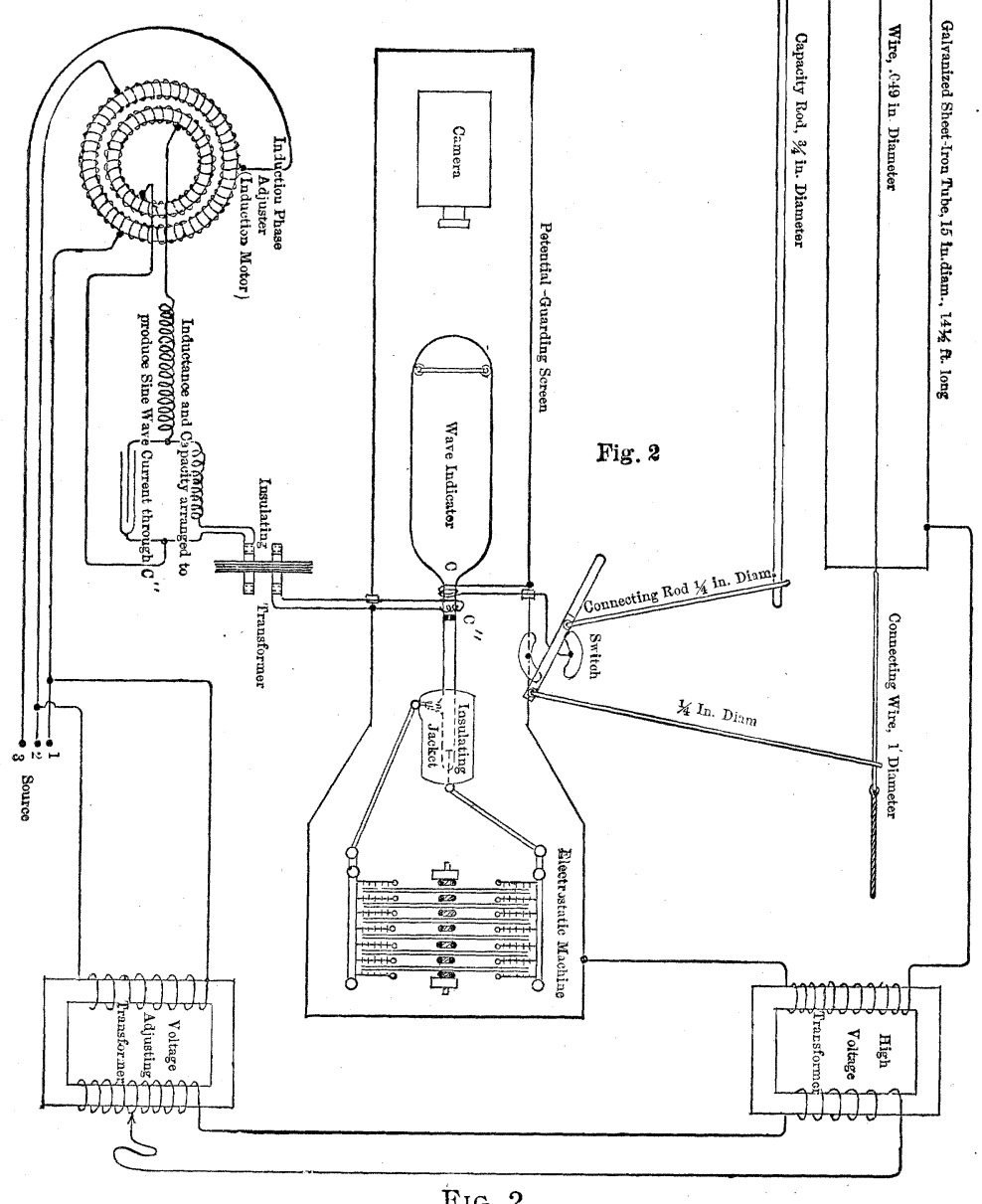

Fig. 2.

that Mershon found. The results obtained were totally different. It became evident from this disagreement that barometric and 
temperature variations exerted important influences. The difference between the approximate results obtained by the author and those of Mershon indicated that the voltage starting the loss between wires would vary as the barometric pressure. When, however, the values deduced from the Telluride results were correspondingly corrected for barometric pressure and applied as eonstants in these equations the voltages observed by Scott for starting the loss on small wires were in no wise predicted. Upon thinking over the probable causes for this, it seemed that the reasons were most likely as follows:

The dielectrically powerful atmospheric film surrounding the small wire would cause the initial rupture to occur at a distance from the surface of the conductor entirely appreciable with respect to the radius of the conductor, in which event some value of $D^{\prime}$ different from $D_{0}$ would be responsible for the initial rupture of the atmosphere. The value of $D^{\prime}$ would be indeterminate so long as we have no means for determining the distance from the surface of the conductor at which the initial rupture occurs. Again, it was apparent that the values of $D^{\prime}$ and the distances at which they occur from the surface of the conductor might vary in an unknown manner relative to the radius of curvature of the conductor.

It became evident that a series of experiments would be necessary in order to obtain all of the data required to write properly the formulas expressing the relation of all the factors that control the start of the atmospheric loss between wires.

It was determined first of all to check by experiment the impression gained from the observations of Scott that the visual appearance of the corona or brush discharge on the wire occurs simultaneously with the initial formation of energy-loss, as the line voltage is raised; and to observe the nature of the charging current with respect to the line-voltage with a view to determining more data regarding the origin of the loss. Should the start of the loss be accompanied simultaneously by the visual appearance of the corona over the wire, this would be an easily discernible fact that would greatly facilitate subsequent experimental work. The point at which the atmospheric conduction-loss would occur in relation to diameters of conductors, their distance apart, applied voltage, barometric pressure, temperature, moisture, and the thickness of the dielectrically powerful but thin zones of atmosphere could then be noted simply by watching for the appearance of the corona. 
For this purpose it was realized that the most convenient and effective laboratory arrangement of the line would be to suspend a single wire for observation at the center of a metallic tube of suitable diameter much the same as originally suggested by Mershon. There are three evident advantages which this arrangement has in laboratory work of this character over the use of a pair of parallel wires.

1. The dielectric flux established about the wire between it and the cylinder is easily and exactly estimated in terms of the dimensions of the wire and cylinder and the dielectric flux-constant or specific inductive capacity of the atmosphere. The flux emanates uniformly from the wire, thus making definite the results deduced from observations.

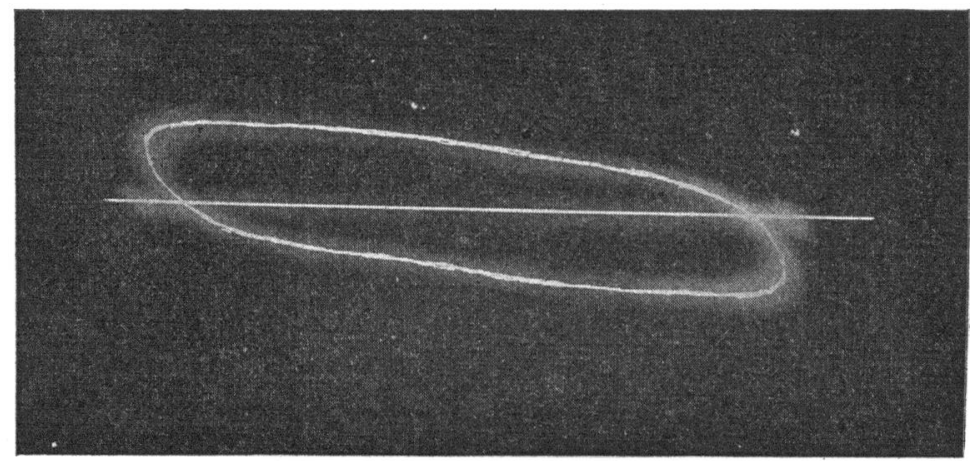

F1G. 3.

2. A lower voltage suffices to cover a given range of experimental study.

3. The tube may easily be made to contain atmosphere at various pressures, temperatures, and degrees of entrained moisture.

At this stage of the work in April, 1903, Mr. H. C. Ford, a senior student in my classes, assisted by Mr. C. L. Wernicke undertook as a thesis to make the experiments. The author is greatly indebted to these young men for the energetic and effective manner in which they did the work.

They erected apparatus, determined and charted results as follows: 
The general plan for observing the details of the corona and loss phenomena due to high voltages with the aid of a cathoderay wave indicator is given in Fig. 2. A brass wire 0.049 inch in diameter was mounted at the center of a galvanized shett iron tube 15 inches in diameter and 14.5 feet long, as shown. Between this wire and the tube high pressure was applied and adjusted to any desired value up to 80000 effective volts by means of the transformers as shown.

The arrangement permitted the coils $C^{\prime}$ of the wave indicator to be inserted by means of a switch, as shown, in series with the

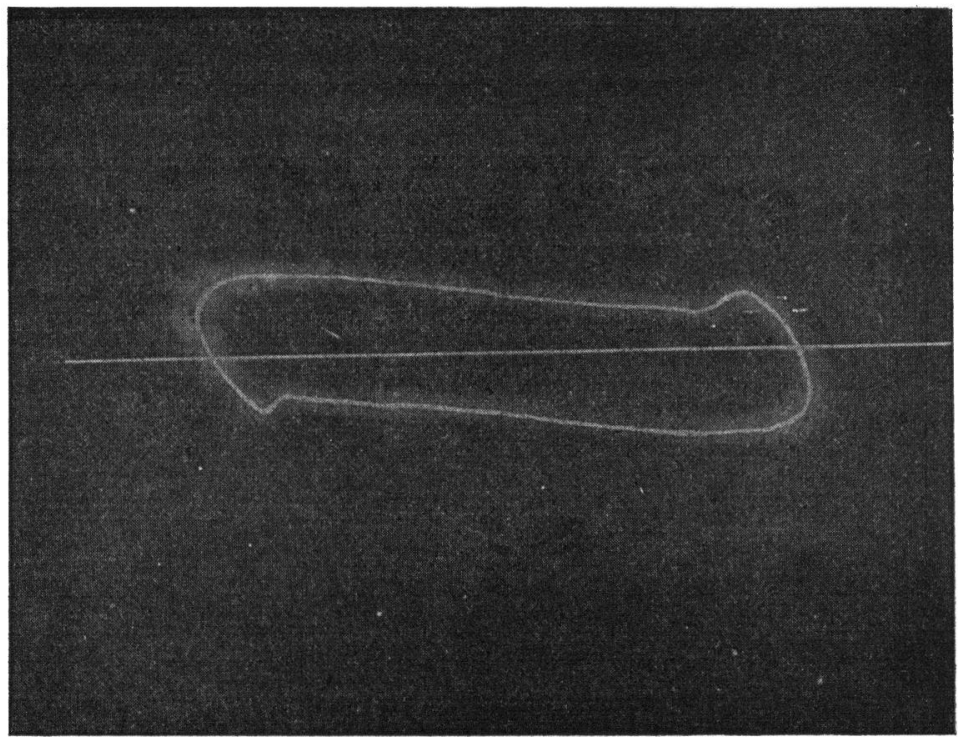

Fig 4

wire so as to indicate whenever desired the charging current set up from thic wire to the cylinder. In order to note at a glance any departure of the wire charging-current the charging-current form that should exist if no atmospheric conduction were present, a 0.75 inch brass rod with well-rounded ends was placed outside the cylinder and connected through the switch to the same terminal of the transformer as the wire. The arrangement was such as to permit quickly the switching of the indicator coil $C^{\prime}$, in series either with the wire or rod Then at low voltages prior to the disruption of the atmosphere about the wire, the indicator 
diagram produced by the wire and rod-charging currents were adjusted to equality by moving the rod in its position relative to the cylinder.

$A$-sine wave current controlled by a proper circuit of inductances and capacity and passed through $C^{\prime \prime}$, produced the known indicator motion.

In the use of high voltages in this manner two precautions must be taken in the use of the wave indicator. It must be entirely enclosed in a potential-guarding screen set up on high-voltage insulators and a connection must be made from the screen to

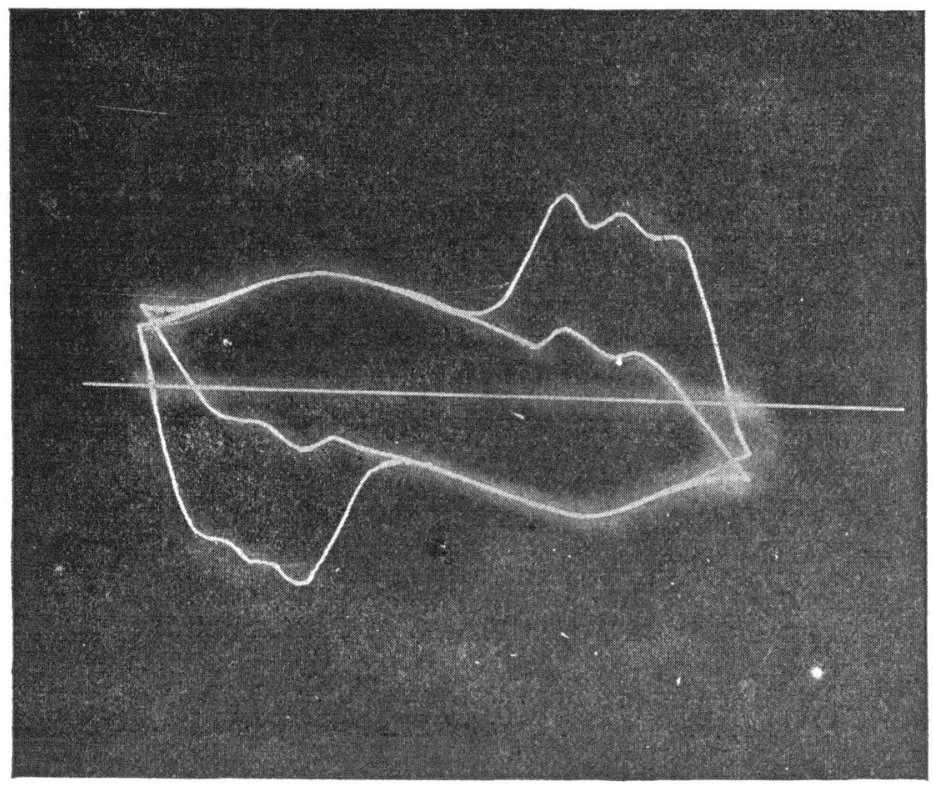

Fig. 5.

the terminal of the transformer that is connected to the wire and capacity-rod. The sine-wave current must pass through an insulating transformer and the secondary must be connected to the guard screen so as to protect the low-voltage source and relieve the indicator of electric stress at all points.

A three-phase source was employed so as to draw for convenience the sine-wave current through an induction phase adjuster as shown. By shifting the sine wave, any intricate part of the unknown wave was made to occur when the sine wave was pass- 
ing through zero and, therefore, changing most rapidly, thus unfolding the intricate portion of the unknown wave so as to be observed and recorded to best advantage.

Figs. 3, 4, 5, and 6 are half-tone reproductions of diagrams of line-wire and capacity-rod charging currents, photographed from the screen of the indicator. Eight of these were observed

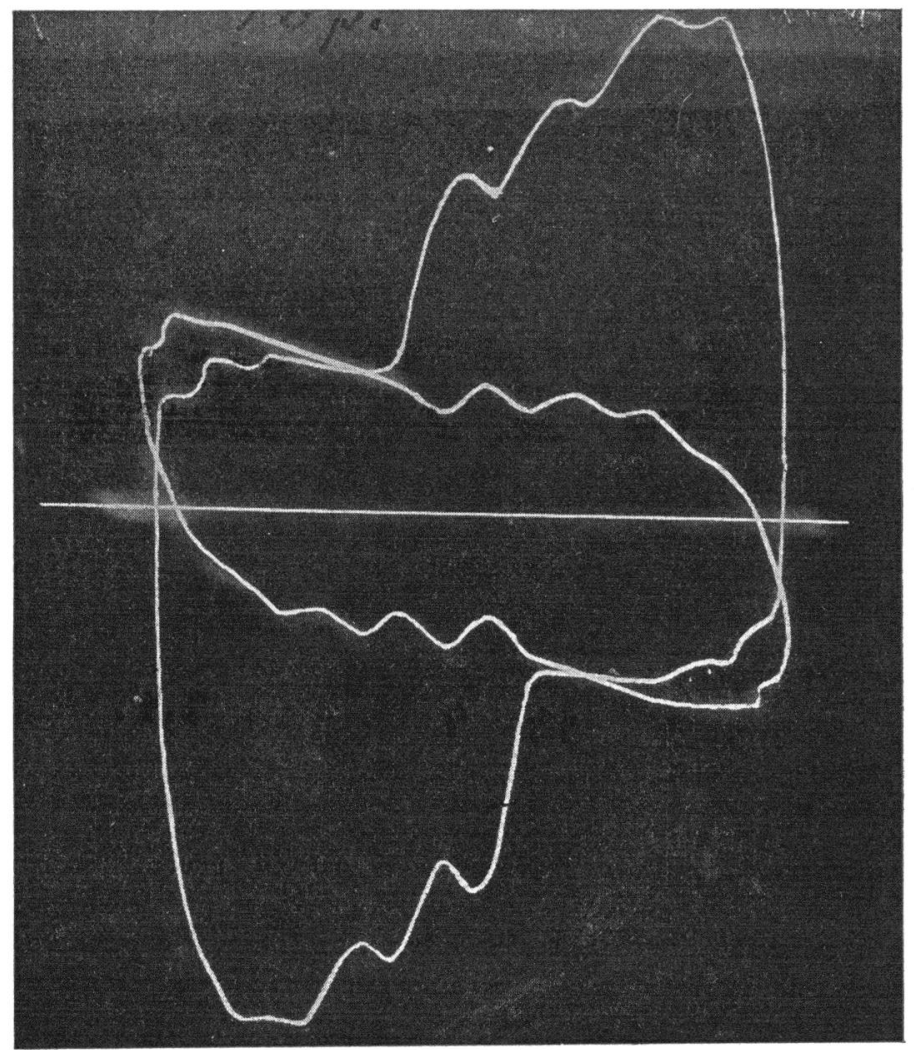

FIG. 6.

in this series at maximum voltage wave values varying from 23000 to 48000 volts. To give a clear idea of the characteristics of these diagrams it is necessary to reproduce only the above four. In Figs. $3^{\prime}, 4^{\prime}, 5^{\prime}$ and $6^{\prime}$ the waves indicated in Figs. 3, 4, 5 and 6 are drawn to scale in rectangular coördinates. They show at once the nature of the phenomena of atmospheric conduction 
giving rise to a loss between wires at high alternating voltages.

The waves of line and condenser charging currents are identical in Pigs. 3 and 3 ', which were observed at a voltage having a maximum value of 23000 . The voltage was not yet high enough to cause the atmosphere about the line-wire to break and become conductive. The charging current applied from the wire to the cylinder was identical with the true capacity chargingcurrent from the rod to the cylinder.

When the voltage was slightly raised, a well-defined though small change in the line charging current appeared as a hump on either side of its indicator diagram, (see Fig. 4), or a sudden increase in the current, just as it was about to pass through zero, as seen in the rectangular coördinate diagram of this same wave shown in Fig. $4^{\prime}$.

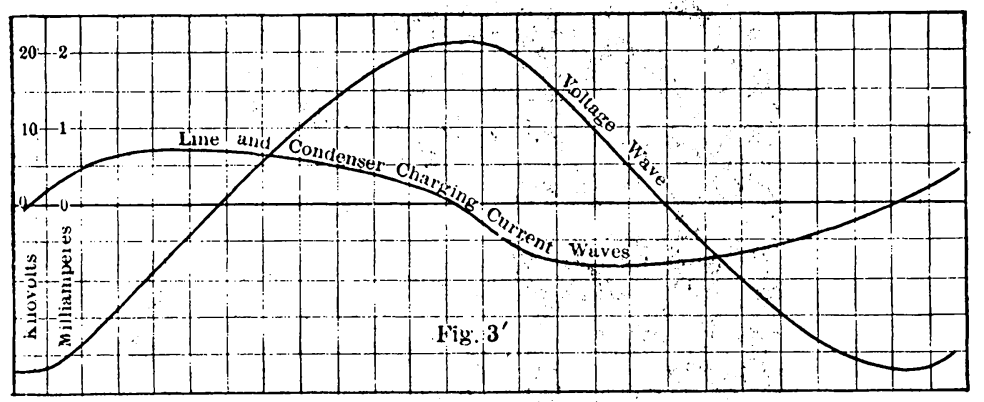

Fig. $3^{\prime}$.

At exactly the same value of voltage at which this hump in the line-current appeared the corona became visible when viewcd in the dark, thus settling definitely this point and proiiding a convenient and reliable guide in subsequent experimental studies.

It should be observed that the manner of departure from normal capacity-form of the line charging current is much as one would cxpect from prior knowledge. After the phenomenon has been started, at that instant in each cycle when the voltage attains a value of 20000 , the atmosphere about the line-wire breaks and forms a conducting envelope about the wire. As the value of the voltage is very near the maximum it follows that the disrupting dielectric strain can last but a brief portion of a cycle. Beyond this the normal true capacity condition will be resumed in which the rod and wire charging currents are again 
in agreement. The atmospheric conducting action in this instance, then, is to increase the capacity of the wire by covering it with a high resistance conducting envelope during that portion of the cycle in which the instantaneous voltage is high enough to maintain in the atmosphere next to the line-conductor a state of strain sufficient to maintain disruption.

Thus it is scen that the electric circuit from the wire to the cylinder changes during the cycle from a state of true and unvarying capacity to one of increased and variable capacity in series with a high resistance.

These two actions evidently contribute to the same result; viz., the establishment of a component of current passing from wire to cylinder that is in phase with the voltage and which, therefore, dissipates energy in heat at a corresponding rate.

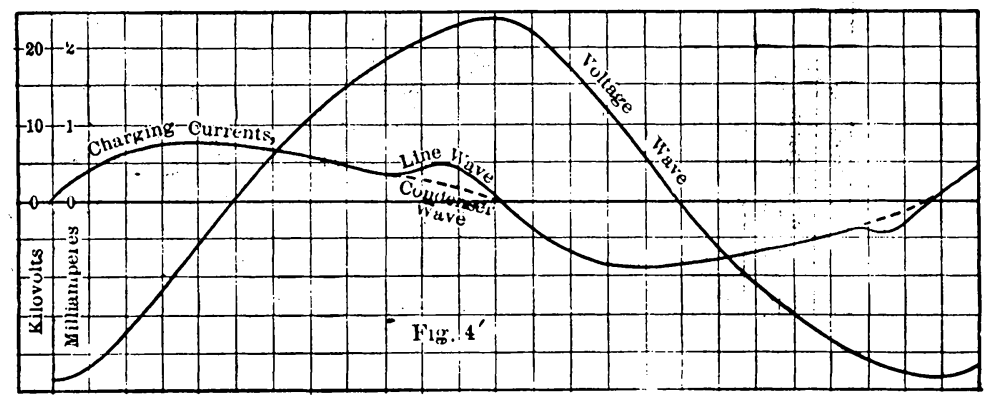

FIG. 4'.

We did not succeed in starting the hump in the line-current wave at a lower voltage than that applied for Figs. 4 or $4^{\prime}$. By raising and lowering the voltage and watching the indicator it was evident that it required a slightly higher instantaneous voltage to start the conduction than that required to maintain it. It is highly probable that the high temperature reached by the conducting envelope, due to heat produced by the current, will account fully for this.

As the voltage is raised the departure of the line chargingcurrent from its normal true capacity form occurs to a remarkable degree. The maximum value of the voltage-wave was set at 26500 volts and the card of Fig. 5 was obtained from which the waves of Fig. $5^{\prime}$ were determined. Qualitatively, there are here observed precisely the same phenomena as in Figs. 4 or $4^{\prime}$. The atmosphere remains conductive during a large part of the cycle 
returning to the normal with corresponding coincidence between the condenser and line currents during the remaining small portion of the cycle. It may be noted that whereas 20000 instantaneous volts were required to maintain a minimum corona in the condition that produced Figs. 5 and $5^{\prime}$, the definitely lower value of 17000 volts is required due again probably to the higher temperature of the ruptured atmosphere.

When the voltage wave was raised to the maximum value of 48000 volts, the cards and corresponding waves in Fig. 6 and $6^{\prime}$ were obtained, while the disruption cvidently occurs at 17000 volts as before. So important a part is now taken by the resistance and fluctuating capacity that there is no longer a continuation at any point throughout the cycle of coincidence between the capacity rod and line-wire charging currents.

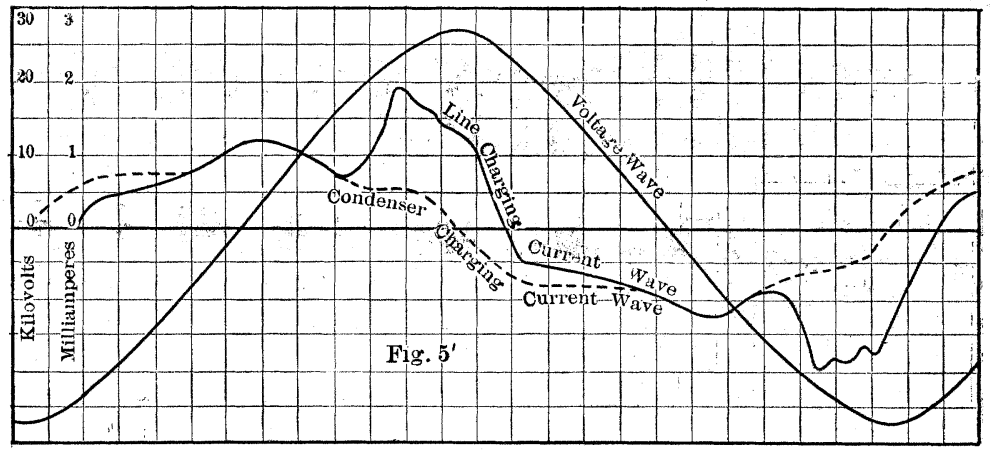

FIG. $5^{\prime}$.

These voltage-waves were determined by integrating the capacity rod charging currents. Their scale was obtained by observing the maximum values by means of a spark-gap. The wave-indicator scale for the currents in the case of each card was easily obtained from the effective value of tho sine-wave current read from an ammeter connected in circuit with the coil $C^{\prime \prime}$.

In all, eight of these cards were taken and worked up in the foregoing manner. Products of the current and voltage waves were made and averaged by integration so as to obtain the watts lost in corona display over the wire at each corresponding alternating voltage applied. These results were charted in Fig. 7, locating the curve there drawn.

The way was now clear to determine experimentally the validity of the expression derived above, provided there was 
some method for determining the distance from the surface of the conductor at which the initial break occurs. I am indebted to Mr. B. T. McCormick, a senior student in my classes last year, for 'a method by means of which this may be accomplished. Assisted by Mr. C. L. Gillespie he applied it to many of the commercial sizes of conductors ranging in diameters from 2 to 625 mils. At the center of the 15 -inch cylinder conductors of various diameters were mounted. An alternating voltage was applied

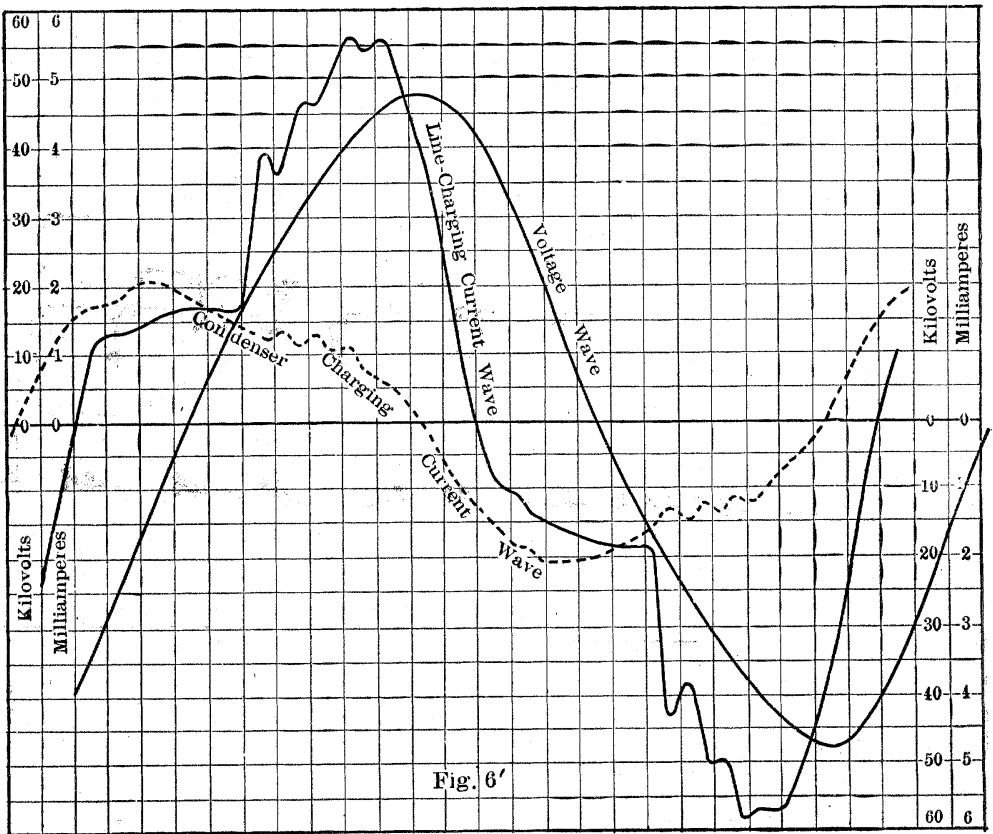

Fig. $6^{\prime}$.

between the conductor and the cylinder and elevated to the point at which corona is first visible in the dark. The diameter of the conductors and the maximum value of the voltage waves were observed by means of the spark-gap. Corresponding to each conductor and the maximum value of the voltage at which its corona was initially formed, curves were located showing the relation between the dielectric fluxdensity and radial distance from the surface of the conductor. These curves were then plotted in rectangular coördinates in tha 
same manner as shown in Fig. 8. The envelope of these curves when taken at sufficiently small intervals of conductor sizes, gives the relation between the distance from the surface of the con-

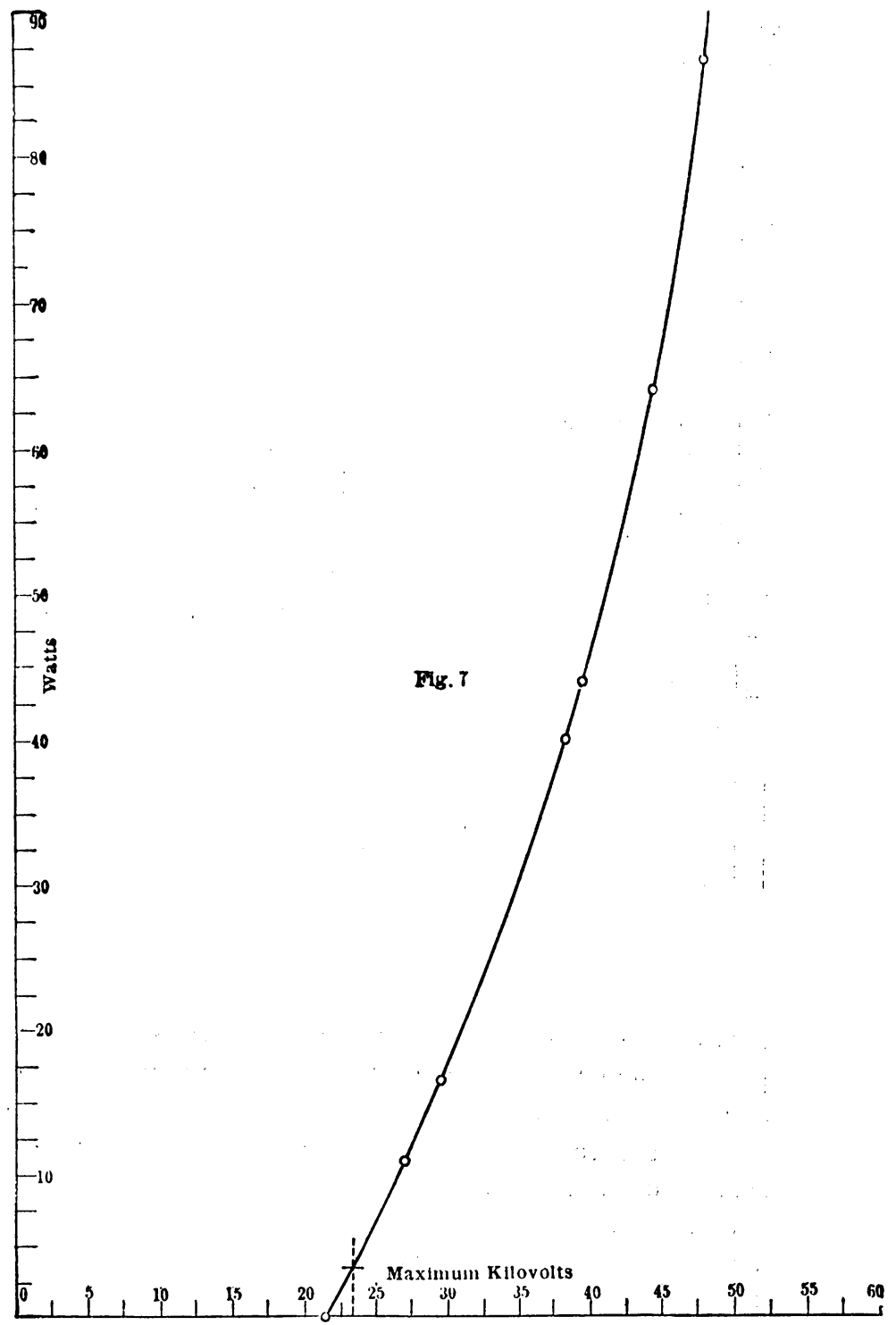

Fig. 7.

ductor and the dielectric flux-density at which the atmosphere first ruptured. In this manner the relation between the conductor-diameter, distance from surface and dielectric flux rup- 
turing density, was determined The values thus determined are given in the Synopsis; i.c., in the tables on page 4 .

One especially interesting feature of the results given in this table is that the distance from the surface of the conductor at

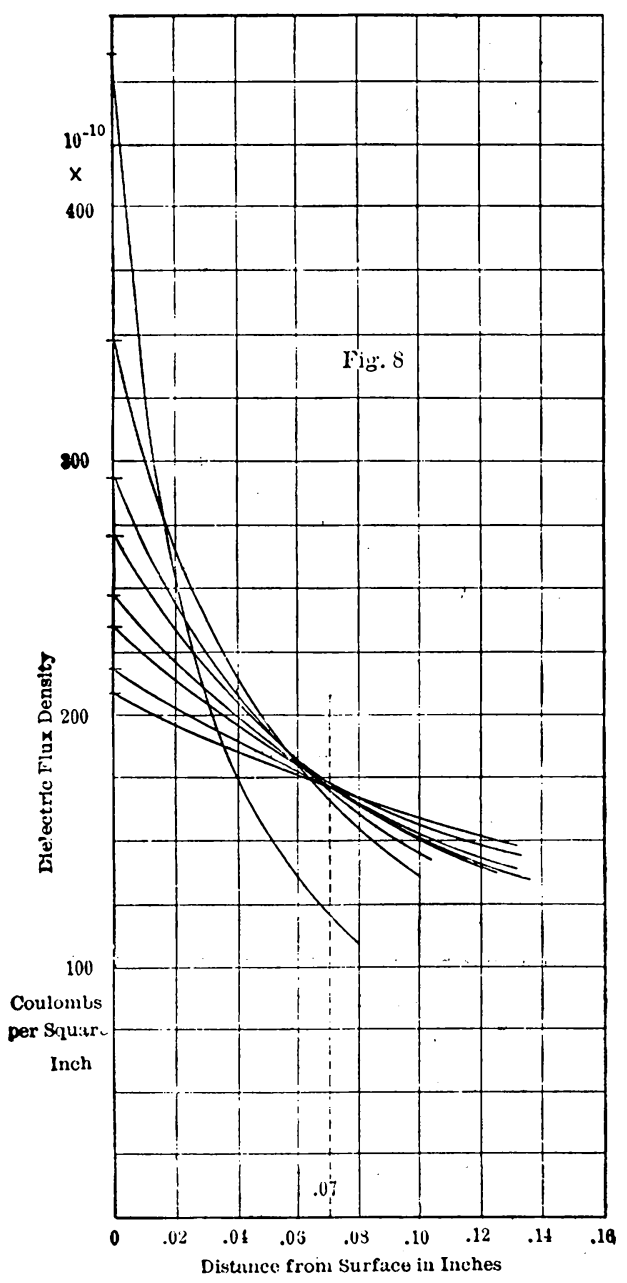

Fig. 8.

which the atmosphere first ruptures is constant at 0.07 inch. for all diameters above $0.2 J$ inch and the corresponding rupturing flux value is constant at $170 \times 10^{-10}$ coulombs per square inch. The largest conductor used in these experiments r as $0.625 \mathrm{inch}$ 
in diameter. It is, however, reasonable to expect that since there is no change in the value of $d$ due to changes in the conductorcurvature when the diameter varies from 0.25 to 0.625 inch, there will be no important change in such value of $d$ for conductors. of larger diameters. At conductor-diameters smaller than 0.25 inch, there is approximately a regular diminution with the diameter, of the distance of the initial rupturing-zone and a corresponding approximately regular rise in the initial rupturing dielectric flux-density.

To study the effects due to varying barometric pressures and temperatures, a conductor 0.125 inch in diameter was mounted at the center of a stout brass cylinder 20 inches long and 8.75 inch.

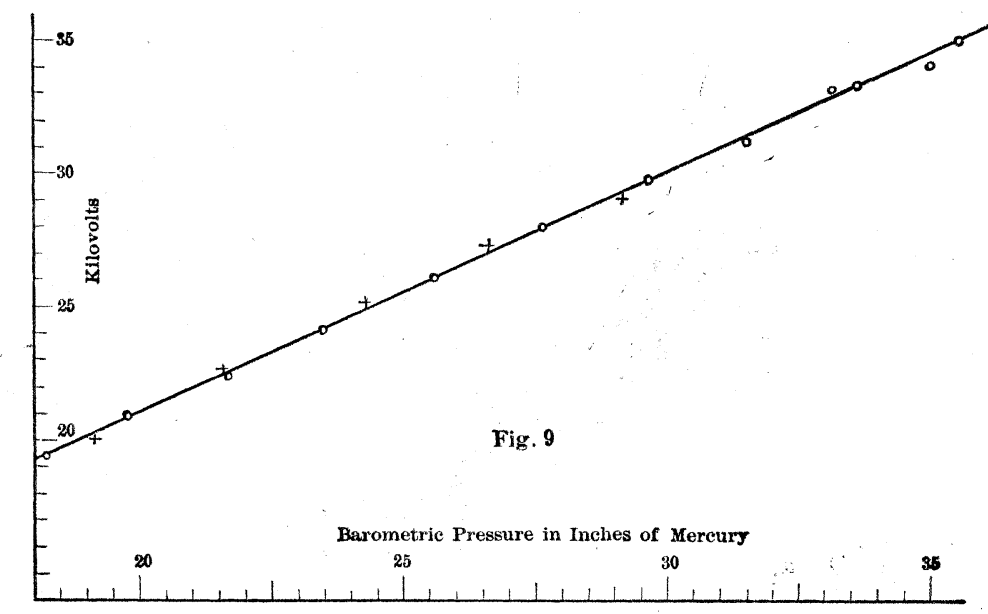

in diameter, provided with packing flanges and closed with 0.5 inch plate-glass at either end. By means of ordinary handpumps and a long mercury U-tube, the atmospheric pressure could be adjusted definitely to any desired value from 18 to 36 inches of mercury. Alternating voltage was applied between the conductor and the cylinder and elevated to the point where the corona was observed in the dark to appear suddenly. The effective values of the voltage were determined by means of a Weston alternating-current voltmeter applied across the terminals of the low-voltage primary of the high-voltage transformer. Throughout all experiments the form of the voltagewaves was approximately the same; viz., that given in Figs. $3^{\prime}$ $4^{\prime}, 5^{\prime}$ and $6^{\prime}$; frequency 130 cycles. 
With the atmosphere in the cylinder at the room-temperature of $70^{\circ}$ fahr., the observations showing the relation between corona starting-voltage and atmospheric pressure were made that are found charted in Fig. 9. They locate a right-line relation, the equation of which is

$$
K_{\mathrm{v}}=0.902 b+2.93
$$

wherein

$K_{\mathrm{v}}=$ effective kilovolts required to start the corona.

$b=$ barometric pressure in inches of mercury.

To determine the effect of variation of temperature upon the voltage required to inaugurate the corona, the air in the tube was heated electrically and cooled by immersion in a salted ice-pack. However, the salted ice method for cooling was not a success and had to be abandoned, it being evident that a much more extensive method of cooling would have to be used in order to maintain the surfaces of the glass plates closing the tube free of moisture, so as to ensure effective insulation and clear vision for the detection of the corona. The cooling facilities that are evidently needed were not at hand when these tests were made, last May, so we had to be contented with such temperature variation of the air as could be obtained by heating the tube electrically by means of a jacket of German-silver wire and asbestos. Observations were made to determine the combined effects of temperature and barometric pressure variation by heating the air in the tube to about $200^{\circ}$ fahr., at a given barometric pressure, then as the temperature dropped slowly by radiation and by maintaining the barometric pressure constant by use of the pump or by natural flow of the atmosphere, the voltage at the various temperatures required to start the corona were observed. The process was then repeated for another barometric pressure until finally observations had been made covering the temperature range of from $70^{\circ}$ fahr., to near $200^{\circ}$ fahr., at barometric presures ranging from 19 to 34 inches. The humidity present was that due to natural causes and was not observed.

A target-diagram of these observations, including those made at $70^{\circ}$ fahr., is shown in Fig. 10. The observations made at room-temperature are much more reliable than those made at other temperatures. The reason for this is the uncertainty of the actual temperature of the atmosphere in contact with the conductor at the center of the tube when at a different temperature from that of the outside atmosphere. The difference in temperature causes a transfer of heat from one side to the other 
that occurs largely by means of convection currents that give rise to the uncertainty of the temperature at the center of the tube. However, the observations made at the constant barometric pressures of 29,26.5 and 19 inches of mercury left no doubt of the nature of the barometer temperature-voltage variation as shown by the lines thus located in Fig, 10 and which indicate a close agreement between the variation of the coronaforming voltages and the atmospheric density.

The fact that there is an addition-constant in the equation for the barometric pressure-kilovolt line for $70^{\circ}$ fahr., in equation (11) shows that the barometric pressure-temperature-corona-forming voltage relation of Fig. 10, will not be accurately expressed in a formula which assumes that the corona-forming voltage varies

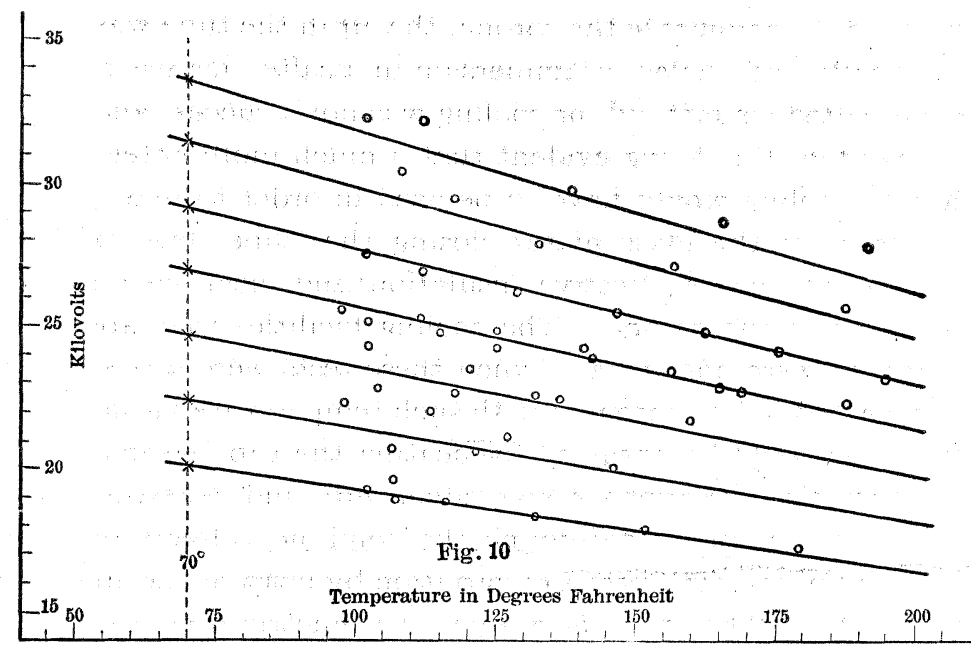

The constant barometric pressures at which the lines in this diagram were located are, beginning at the top : $34,31.5,29,26.5,24,21.5$, and 19 inches of mercury.

exactly as the density of the atmosphere. However upon trial it was found that the assumption that it does so vary will provide an expression giving the results charted in Fig. 10 with sufficient accuracy for practical purposes.

The corresponding correction-factor to be applied to equation (9), to account for barometric pressure effects different from 29.5 inches of mercury and temperatures different from $70^{\circ}$ is

$$
\frac{17.94 b}{459+t}
$$

wherein

$b \mathrm{i}$ the barometric pressure in inches, and

$t$ th temperature in degrees on the Fahrenheit scale. 
The final equation which allows for all important factors showing the relation between the instantaneous maximum voltage, size, and separation of conductors, rupturing value of dielectric flux, and distance from the surface of the conductor at which the rupture occurs, causing initial corona formation should, therefore, be written

$E_{\max }=\frac{17.94 b}{459+t} \times 2055 \log _{10}\left(\frac{s}{r}\right) D^{\prime}(r+d) \times 10^{-10}$

A determined effort was made to observe the effect upon the point of initial corona formation due to the presence of moisture in the atmosphere. The ordinary air in the tube was displaced with dry air and the corona-starting voltage was then observed. Steam was then admitted to the interior of the cylinder and after allowing sufficient time for the water that was not absorbed by the air to settle upon the walls of the cylinder, the corona voltage was again observed. By this method the effect of the presence of humidity could not with certainty be detected, leading one to conclude that such effect if it does exist is small.

Where the conductors are 0.25 inch or larger in diameter, $D^{\prime}$ and $d$ remain uniform at

$$
\begin{aligned}
& D^{\prime}=170 \times 10^{-10}, \text { coulombs per sq. in., and } \\
& d=0.07 \mathrm{inch}
\end{aligned}
$$

and equation No. (12) becomes

$$
E_{\max }=\frac{17.94 b}{459+t} \times 350000 \log _{10}\left(\frac{s}{r}\right)(r+.07)
$$

The data for Mershon's experimental line are

$s .=15,22,35$, and 52 inches.

$r=0.081$ inch.

$D^{\prime}=200 \times 10^{-10}$ coulombs per sq. in.

$d=0.035$, inch.

$t=$ about $60^{\circ}$ fahr.

$b=$ about 20 in.

$1.71=$ approximate ratio of maximum to effective value of voltage wave.

Upon substituting these values in equation (12), the following results are obtained. 


\begin{tabular}{c|c|c}
\hline $\begin{array}{c}\text { Separation of } \\
\text { Lines. }\end{array}$ & $\begin{array}{c}\text { Effective Voltage } \\
\text { at which } \\
\text { Initial Corona } \\
\text { Loss Occurs. }\end{array}$ & $\begin{array}{c}\text { Mershon's } \\
\text { Observations } \\
\text { Effective } \\
\text { Voltage. }\end{array}$ \\
\hline Inches. & & \\
15 & 43600 & 43500 \\
22 & 46800 & 47000 \\
35 & 50700 & 49000 \\
52 & 54000 & 53500 \\
\hline
\end{tabular}

In this table the values labelled "Mershon's Observations" were taken at the point of intersection of the voltage base-line in Fig. 1 formed by the broken-line extension of the vertical portion of the loss-curves. Mershon's conclusion is that the small loss portion, i.e., the horizontal portion of these loss-curves, is due to the line insulators while the large increase of loss beyond the sharp rise in the curve is due only to the atmospheric loss. The laboratory tests confirm this fully. Some will insist that if this is strictly so the sudden rise in the loss-curve should make an abrupt and not a gradual turn upwards. Upon further thought it must be evident, however, that as the-voltage is raised atmospheric conduction will first appear over the sections of the wire in contact with the insulators which have a higher specific inductive capacity, i.e., a higher permeability to dielectric flux than the atmosphere, causing the electrostatic field about the wire in the neighborhood of the insulators to be higher than in a position remote therefrom. On this account the initial start of the atmospheric conduction-loss will not appear abruptly when the voltage is increased gradually through the corona-forming value. It is to be noted that the vertical portions of these loss-curves as extended to the base of the diagram, form curves having substantially the same character as the corresponding laboratory loss-curve given in Fig. 7. It is from this point of view that the above method was employed for locating the value of the voltages that started the corona losses on the Telluride line.

Professor Harold B. Smith has erected an experimental highvoltage line at Worcester Polytechnic Institute, 250 feet long, upon which conductors have been mounted varying in size from No. 10 to No. 2 B. \& S. G. and high-voltage losses have been measured, due to electromotive forces ranging from low values to 
upwards of 250000 volts. He has very kindly given me three of his voltage-line-loss curves taken from these lines, arranged as follows:

Length of lines, 250 feet. Observed May 14, 1901; May 3 and 28,1902 . Barometric pressure 29.5 inches; temperature, $70^{\circ}$ fahr. Curve No. 1. Size of wire No. 10 B. \& S. gauge. Separation 30 inches, voltage-line losses measured over a range from 30000 to 100000 volts.

Curve No. 2. Size of wire No. 2, B. \& S. gauge., separation 24 inches, voltage-line losses measured over a range from 30000 to 145000 volts.

Curve No. 3. Size of wire, No. 2 B. \& S. gauge., separation 48 inches, voltage-line losses observed over a range from 30000 to 150000 volts.

For a No. 10 B. \& S. gauge wire:

$$
\begin{aligned}
& d=0.018 \text { inch. } \\
& r=0.05095 \text { inch. } \\
& D^{\prime}=275 \times 10^{-10} .
\end{aligned}
$$

No. 2 B. \& S. gauge wire,

$$
\begin{aligned}
& d=0.07 \text { inch. } \\
& r=0.1288 \text { inch. } \\
& D^{\prime}=170 \times 10^{-10} .
\end{aligned}
$$

Substituting numerical values in equation (13) for the two No. 2 lines and in (12) for the No. 10 line, the following results are obtained for comparison with the measurements by Smith. (See table on page 304.)

Smith's roltage-measurements were made with a special and highly satisfactory form of electrometer. Strict agreement of the calculated and effective results cannot, however, be expected without a knowledge of the ratio of the maximum to the effective values of the actual high-voltage waves impressed upon the line. The last column in the above table gives these corresponding maximum effective ratios that would bring the calculated and experimental results into exact agreement. The ratios indicate the use of a somewhat peaked line-voltage wave which is apt to be the case owing to the distortion produced in the high-pressure transformer by the delivery of the line charging-current.

Naturally the conductor having a circular exterior section is the one best adapted, other things being equal, for the avoidance of atmospheric loss. The ordinary stranded cable exposes nearly a circular sectional area, so that in respect to the avoidance of this sort of loss the cable should give substantially the same 
results as the solid conductor. Evidently when the voltage is such as to demand a greater exterior diameter of conductor than that corresponding to the solid section required for the economical or efficient transmission of the current, the solid or stranded

\begin{tabular}{|c|c|c|c|c|}
\hline Line. & $\begin{array}{c}\mathrm{E}_{\max } \\
\text { Maximum in- } \\
\text { stantaneous } \\
\text { voltage } \\
\text { at which } \\
\text { corona loss } \\
\text { occurs, } \\
\text { determined } \\
\text { by equations } \\
\text { (12) or (13). }\end{array}$ & $\begin{array}{c}\mathrm{E}_{\mathrm{ff} .} \\
\text { Reduced } \\
\text { from } \\
\mathrm{E}_{\mathrm{max} .} \text { by } \\
\text { the } \\
\text { factor } \\
\sqrt{2=1.415}\end{array}$ & $\begin{array}{c}E_{\mathrm{ff}} \\
\text { Observed by } \\
\text { Smith. } \\
\text { (Located by } \\
\text { intercept } \\
\text { upon } \\
\text { voltage axis } \\
\text { of voltage- } \\
\text { watt curve as } \\
\text { was done in } \\
\text { connection } \\
\text { with } \\
\text { Mershon's } \\
\text { curves, Fig. 1.) }\end{array}$ & $\begin{array}{l}\frac{\mathrm{E}_{\max }}{\mathrm{E}_{\mathrm{ff}}} \\
\text { As a factor } \\
\text { in } \mathrm{i}=\mathrm{u} \\
\text { of } \sqrt{ } 2 \\
\text { required to } \\
\text { bring } \\
\text { calculated } \\
\text { and } \\
\text { observed } \\
\text { results into } \\
\text { exact } \\
\text { agreement. }\end{array}$ \\
\hline $\begin{array}{l}\text { No. } 10 \\
\text { B. \& S. G. } \\
30 \text { in. } \\
\text { separation. }\end{array}$ & 107700 & 76000 & 66000 & 1.63 \\
\hline $\begin{array}{l}\text { No. } 2 \\
\text { B. \& S. G. } \\
24 \text { in. } \\
\text { separation. }\end{array}$ & 158000 & 112000 & 100000 & 1.58 \\
\hline $\begin{array}{l}\text { No. } 2 \\
\text { B. } \& \text { S. G. } \\
48 \text { in. } \\
\text { eparation. }\end{array}$ & 178500 & 126000 & 110000 & 1.61 \\
\hline
\end{tabular}

conductor can be made hollow or provided. with a non-conducting core. A few observations were made by using round, hexagonal, and square conductors at the center of a 15 -inch cylinder for the 
purpose of obtaining comparative data, applicable to the coronaforming voltage as affected by those forms of sections. These observations are charted in Fig. 11, from which it is seen that while the exterior surface and total section of the hexagonal conductors are greater than for the same thicknesses of round conductor, yet the corons-losses are started at lower voltages. The same is true naturally to a greater extent for the square conductor. The cause of this is obviously due to the concentration of the dielectric flux at the surface-angles of the non-circular sectioned rods.

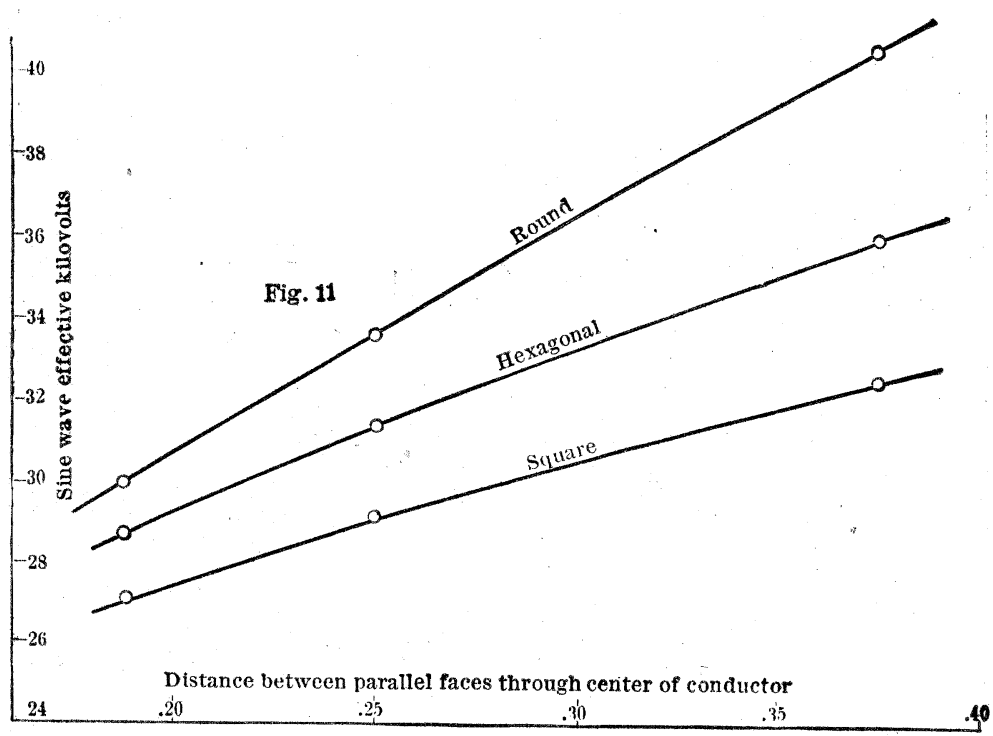

The curves in Figs. 12 and 13 were determined from observations made in the thesis work of Ford and Werhicke, and McCormick and Gillespie. They are reproduced here because they constitute original data that are useful for analogous purposes other than those to which they were applied in this paper. The curves labelled "Sine Wave Effective Kilovolts " give the relation between the voltages and diameters of conductors mounted at the center of the 15-inch cylinder at which initial corona occurred for a diameter range of 3 to 600 mils. The remaining curves give the corresponding calculated dielectric flux-densitics at the conductor surfaces. The voltages were determined by a spark-gap discharger having a scale laid off in terms of sine wave effective volts. 
A Substitute for the Spark-gap Method for Gauging the Mamixum Values of High Voltages.

The maximums of the highest alternating voltage-waves may

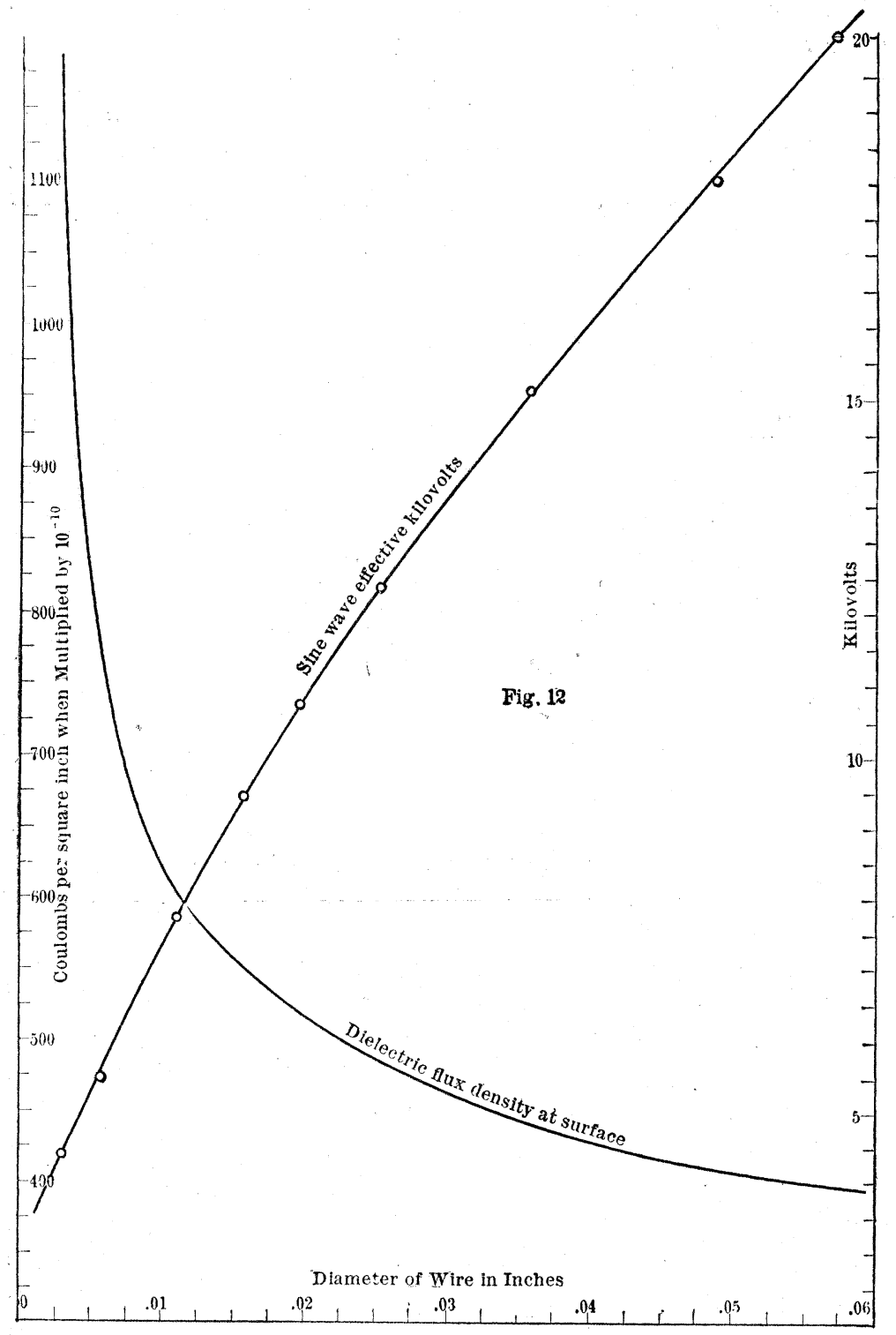

be gauged easily when applied between wires of suitable diameter the separation of which is adjusted until the initial corona appears 
in the dark. From the conductor diameter and separation, barometric pressure and temperature, a determination of the

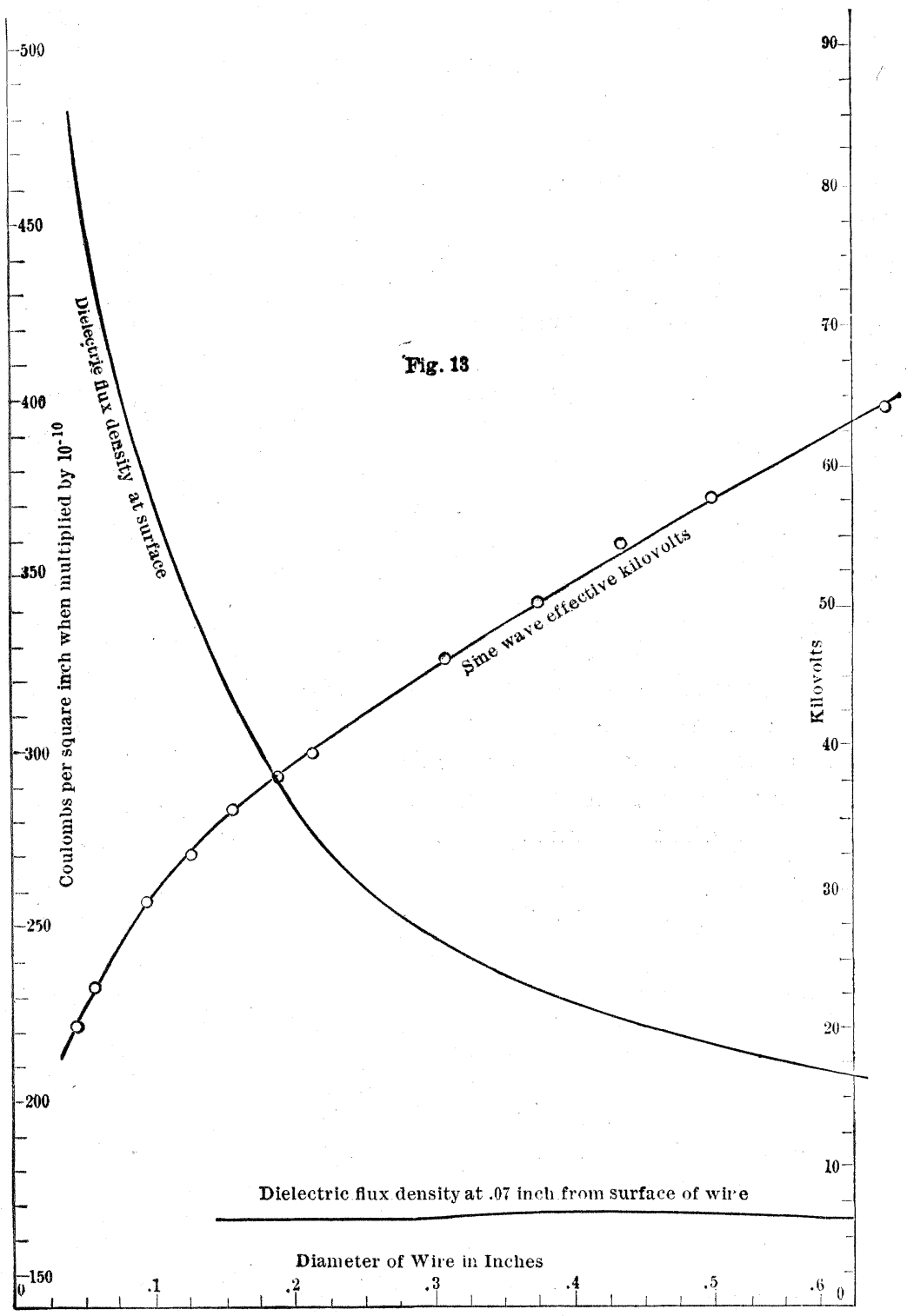

maximum of the voltage-wave may easily be made that will be just as accurate as the constants in the equation (10), or the location of the curves in Figs. 12 and 13, or made with such 
increased accuracy as will be obtained in similar determinations in the future. This method is free from the fluctuating indications and objections that attend the use of the spark-gap, while its only real objection is that the observations must be made in a place that is moderately dark.

In conclusion, attention is called to the fact that no experiments were made to determine the effects that the presence of rain and snow in the atmosphere have upon the point of initial corona formation. It appears from Mershon's Telluride results that there will be little effect from this cause.

With regard to the effect of the presence of smoke it should be said that there is evidence that a very slight loss is produced at all voltages, which is greater at the higher values due to this cause. During the spring of 1903, on days when the atmosphere was very smoky on account of neighboring forest fires, Dr. Blaker observed in the Physical Laboratory at Cornell that the conductive discharge through the atmosphere was appreciable when a continuous voltage of 15000 was applied between wires of such size and separation that no detectable conduction occurred when the atmosphere cleared.

Those who have made line observations and who may use them to check the results given in this paper, must not fail to eliminate, first, the effects due to the presence of the supporting insulators.

It is altogether unlikely that changes in frequency, even over wide ranges, will affect appreciably the voltage at which atmospheric conduction is started when all other conditions remain the same. 